\title{
The evolution and distribution of phage ST160 within Salmonella enterica serotype Typhimurium
}

\author{
M. PRICE-CARTER ${ }^{1} \uparrow$, P. ROY -CHOWDHUR Y ${ }^{1,2} \uparrow$, C. E. POPE ${ }^{2 \dagger}, \mathrm{S}_{\text {. PAINE }}^{3}$, \\ G. W. DE LISLE ${ }^{1}$, D. M. COLLINS ${ }^{1}$, C. NICOL ${ }^{3}$ AND P. E. CARTER ${ }^{2 *}$ \\ ${ }^{1}$ Infectious Diseases Group, AgResearch NCBID Wallaceville, PO Box 40063, Upper Hutt, New Zealand \\ ${ }^{2}$ ESR Ltd, Kenepuru Science Centre, PO Box 50348, Porirua, New Zealand \\ ${ }^{3}$ ESR Ltd, NCBID Wallaceville, PO Box 40158, 5140 Upper Hutt, New Zealand
}

(Accepted 13 September 2010; first published online 18 October 2010)

\section{SUMMARY}

Salmonellosis is an internationally important disease of mammals and birds. Unique epidemics in New Zealand in the recent past include two Salmonella serovars: Salmonella enterica subsp. enterica serovar Typhimurium definitive type (DT) 160 (S. Typhimurium DT160) and $S$. Brandenburg. Although not a major threat internationally, in New Zealand $S$. Typhimurium DT160 has been the most common serovar isolated from humans, and continues to cause significant losses in wildlife. We have identified DNA differences between the first New Zealand isolate of $S$. Typhimurium DT160 and the genome-sequenced strain, $S$. Typhimurium LT2. All the differences could be accounted for in one cryptic phage ST64B, and one novel P22-like phage, ST160. The majority of the ST160 genome is almost identical to phage SE1 but has two regions not found in SE1 which are identical to the P22-like phage ST64T, suggesting that ST160 evolved from SE1 via two recombination events with ST64T. All of the New Zealand isolates of DT160 were identical indicating the clonal spread of this particular Salmonella. Some overseas isolates of $S$. Typhimurium DT160 differed from the New Zealand strain and contained SE1 phage rather than ST160. ST160 was also identified in New Zealand isolates of $S$. Typhimurium DT74 and $S$. Typhimurium RDNC-April06 and in $S$. Typhimurium DT160 isolates from the USA. The emergence of $S$. Typhimurium DT160 as a significant pathogen in New Zealand is postulated to have occurred due to the sensitivity of the Salmonella strains to the ST160 phage when $S$. Typhimurium DT160 first arrived.

Key words: Epidemiology, molecular biology, Salmonella Typhimurium.

\section{INTRODUCTION}

Non-typhoidal salmonellosis ranks second among the most frequently reported gastrointestinal diseases in humans in New Zealand, and third among diseases

\footnotetext{
* Author for correspondence: Dr P. E. Carter, ESR Ltd, 34 Kenepuru Drive, PO Box 50 348, Porirua, New Zealand.

(Email: Philip.Carter@esr.cri.nz)

$\dagger$ These authors contributed equally to this work.
}

worldwide [1]. In New Zealand, two Salmonella serovars have emerged as major epidemic strains in the recent past, Salmonella enterica subsp. enterica, serovar Typhimurium (definitive type or phage type) DT160 (S. Typhimurium DT160) and $S$. Brandenburg [2-4]. This contrasts with the serovars causing global pandemics, $S$. Enteritidis PT4 and $S$. Typhimurium DT104 $[5,6]$ neither of which are significant causes of infection in New Zealand. Surveillance reports 
Table 1. Strains for subtractive hybridization and phage isolation

\begin{tabular}{llll}
\hline \hline Strain & Salmonella serovar/subtype & Year isolated & Source/country \\
\hline NZRM4363 & S. Typhimurium LT2 & 1948 & ATCC700720/USA \\
NZRM4347 & S. Typhimurium DT160 & 1998 & Human/NZ \\
TT23564 & S. Typhimurium LT2 fels-2 Gifsy2 $^{-}$Gifsy $^{-}$cam $^{\text {R }}$ & 2002 & Roth Lab/USA \\
\hline \hline
\end{tabular}

published by the Institute of Environmental Science and Research Limited (ESR) show that since 1997 the reported incidence of salmonellosis caused by $S$. Typhimurium DT160 throughout New Zealand has increased with a major epidemic occurring around 2001 [7, 8]. Although reported incidences have decreased somewhat since then, $S$. Typhimurium DT160 remains the single most common cause of salmonellosis in humans in New Zealand [3, 8, 9].

The host range of $S$. Typhimurium DT160 includes humans, farmed animals and wild birds $[3,10]$. Although the strain is not a major cause of salmonellosis internationally it frequently causes gastrointestinal disease in humans and other mammals in New Zealand, and widespread mortality in birds due to septicaemia [2,9]. It is possible that the New Zealand isolates of $S$. Typhimurium DT160 have acquired gene(s), probably by horizontal gene transfer, that have enabled them to emerge as epidemic pathogenic strains in this geographically isolated country. The aim of this study was to identify candidate genes that may have enabled $S$. Typhimurium DT160 to become established and persist in human and animal populations in New Zealand.

\section{METHODS}

\section{Bacterial strains and culture conditions}

The Salmonella strains used in this study are listed in Table 1. Salmonella strains were incubated aerobically at $37^{\circ} \mathrm{C}$ on Tryptic Soy (for subtractive hybridization and DNA purification) or Luria-Bertani (LB) broth or agar plates (for phage work). All Escherichia coli strains which hosted the subtractive genomic DNA library were grown in LB medium supplemented with $50 \mu \mathrm{g} / \mathrm{ml}$ ampicillin or $50 \mu \mathrm{g} / \mathrm{ml}$ kanamycin, under similar conditions to those used for the Salmonella cultures.

\section{Purification of phage}

Phages were purified from the spent media of uninduced stationary phase cultures or from induced cultures $2 \mathrm{~h}$ or $16 \mathrm{~h}$ after adding mitomycin $\mathrm{C}$ (final concentration $2 \mu \mathrm{g} / \mathrm{ml}$ ) at mid log phase [11], using phage-deficient host strain, TT23564 (Table 1). Phage plaques were transferred from agar into the tips of

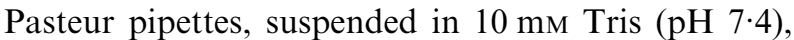
$15 \mathrm{~mm} \mathrm{NaCl}, 10 \mathrm{~mm} \mathrm{MgSO}_{4}$ and 3.4\% chloroform, and stored at $4{ }^{\circ} \mathrm{C}$. For preparation of high-titre phage stocks, phages were propagated by mixing approximately $10^{13}$ p.f.u. in $0 \cdot 7 \times$ LB broth, $0 \cdot 5 \times$ no citrate $\mathrm{E}$ media [12], $1 \mathrm{~mm} \mathrm{MgSO}_{4}, 10 \mathrm{~mm}$ glucose with onefourteenth volume of TT23564 overnight LB liquid culture and incubating overnight with shaking at $37^{\circ} \mathrm{C}$. Cell debris was removed by centrifugation and filtration, and stock solutions stored in $5 \%$ chloroform at $4{ }^{\circ} \mathrm{C}$. Titres for these stocks ranged from 0.5 to $2 \times 10^{15}$ p.f.u. $/ \mathrm{ml}$.

\section{Generalized transduction assays}

To determine whether the $S$. Typhimurium DT160 phage was capable of transferring Salmonella DNA between Salmonella hosts, phage propagated on the chloramphenicol-resistant strain TT23564 was used to test for the transfer of drug resistance to the chloramphenicol-sensitive strain, LT2. For this assay, $100 \mu \mathrm{l}$ of high-titre phage stock $\left(10^{15}\right.$ p.f.u. $\left./ \mathrm{ml}\right)$ was mixed with $100 \mu \mathrm{l}$ of an overnight LB culture of LT2, and the mixture spread onto LB agar medium and grown overnight at $37^{\circ} \mathrm{C}$. The resulting cell lawns were then replica-plated onto LB agar medium containing chloramphenicol at a final concentration of $10 \mu \mathrm{g} / \mathrm{ml}$ and grown overnight at $37^{\circ} \mathrm{C}$.

\section{Transmission electron microscopy (TEM)}

High-titre phage stock was diluted 50 -fold into $1 \mathrm{mg} /$ ml BSA and deposited onto Formvar/carbon grids, negatively stained in $2 \%$ potassium phosphotungstinate $(\mathrm{pH} 7 \cdot 0)$ and examined on a Philips CM10 transmission electron microscope.

\section{DNA purification}

Genomic DNA for suppression subtractive hybridization (SSH) and Southern blotting experiments 
was prepared using the $\mathrm{CTAB} / \mathrm{NaCl}$ method [13]. For the gene survey experiments, a High Pure PCR template preparation kit (Roche, New Zealand) was used. Phage DNA was prepared from the filtered spent media of high-titre solutions. Phages were pelleted by centrifugation, re-suspended in one-tenth volume of TMK [20 mM Tris (pH 8.0), $\left.2 \mathrm{~mm} \mathrm{MgCl}_{2}, 50 \mathrm{~mm} \mathrm{KCl}\right]$ and incubated overnight at $4{ }^{\circ} \mathrm{C}$ with $1.6 \mathrm{mg} / \mathrm{ml}$ DNase 1 and $0.5 \mathrm{mg} / \mathrm{ml}$ RNase A to remove residual bacterial nucleic acids. DNA was purified following $\mathrm{SDS} /$ proteinase $\mathrm{K}$ treatment, phenol extraction and isopropanol precipitation.

\section{Subtractive DNA hybridization}

A SSH library was constructed using a PCR-Select bacterial genome subtraction kit (Clontech, USA) according to the manufacturer's recommendations. DNA from the first isolated human $S$. Typhimurium DT160 strain (NZRM4347) was used as the tester and DNA from the genome-sequenced strain $S$. Typhimurium LT2 (ATCC 700720) was used as the driver. Tester-specific DNA fragments were amplified using a primary suppressive PCR; enriched using a secondary PCR and cloned into pCR4 TOPO (Invitrogen, New Zealand) cloning vector. The library was propagated in TOP 10 chemically competent cells (Invitrogen). The cloned DNA fragments were sequenced and the data analysed using DNAMAN version 4.02 (Lynnon BioSoft, Canada). BlastN and BlastX (www.ncbi. nlm.nih.gov/blast) programs were used to search for similar sequences [14].

\section{Phage genome sequencing and annotation}

Purified phage DNA was sequenced at the Department of Anatomy and Structural Biology, University of Otago, on a Genome Sequencer 20454 GS FLX sequencing instrument. Open reading frames (ORFs) were identified using three different analysis programs: WebGeneMark.hmm [15], NCBI Open Reading Frame Finder (ORF Finder) from the National Centre for Biotechnology Information website (http:// www.ncbi.nlm.nih.gov/gorf/gorf.html) and Genamics Expression v. 1.00 software (Genamics, New Zealand). All putative ORFs of $\geqslant 100 \mathrm{bp}$ were scanned against the GenBank databases using the BLAST suite of programs. The Genbank results for each ST160 ORF against SE1, ST104, P22 and ST64T, if applicable, are provided in Supplementary Table 1 (available online). Sequencing of phage PCR products from a range of
Salmonella strains was performed by conventional sequencing.

\section{orf23 PCR assay}

Salmonella serovars were screened for the presence of ST160 using a PCR assay that targeted orf 23 , which was only found in ST160 and SE1. PCR amplification was performed using AmpliTaq Gold ${ }^{\circledR}$ PCR Master Mix (Applied Biosystems) and the primers orf23-for (5'-GTCTTTCGAACTGCTGGA) and orf23-rev (5'AACCAATGCCGAAGTCA). The amplification reactions $(25 \mu \mathrm{l})$ contained $1 \mu \mathrm{l}$ purified DNA, and $0 \cdot 2 \mu \mathrm{M}$ of each primer. Amplification conditions were as follows: an initial denaturing step of $94{ }^{\circ} \mathrm{C}$ for $5 \mathrm{~min}$, followed by 35 cycles of $95^{\circ} \mathrm{C}$ for $15 \mathrm{~s}, 55^{\circ} \mathrm{C}$ for $15 \mathrm{~s}$, then $72^{\circ} \mathrm{C}$ for $30 \mathrm{~s}$, with a final elongation step of $72{ }^{\circ} \mathrm{C}$ for $7 \mathrm{~min}$. Following amplification, $5 \mu \mathrm{l}$ of the amplification product was analysed by agarose gel electrophoresis.

\section{Southern blot analysis}

Purified DNA from a variety of Salmonella strains was digested with $\mathrm{NcoI}$ (NEB, New Zealand), electrophoresed through a $1 \%$ agarose gel and transferred to a Zeta probe nylon filter (Bio-Rad, New Zealand) for Southern blotting. Filters were hybridized with a purified orf $23 \mathrm{PCR}$ product labelled with $\left[{ }^{32} \mathrm{P}\right] \mathrm{dCTP}$ by nick translation.

\section{Identification of SE1 and ST160 within $S$. Typhimurium isolates}

Two regions that differed significantly between ST160 and SE1 (Fig. 1) were amplified and characterized using primers, Reg1F (5'-GTTGCTGCATAATCGCTGAA) and Reg1R (5'-TTCCGTTCGTATCACGTCAG) for Region 1, and Reg2F (5'-AAGAAACGACGACGAGAGGA) and Reg2R (5'-GAGCTAATGCCGTTCCTTCA) for Region 2. The amplification reactions $(50 \mu \mathrm{l})$ contained $1 \mu \mathrm{l}$ purified DNA, and $0 \cdot 2 \mu \mathrm{m}$ of each primer. The amplification conditions were as follows: an initial denaturing step of $94^{\circ} \mathrm{C}$ for $2 \mathrm{~min}$, followed by 35 cycles of $95^{\circ} \mathrm{C}$ for $30 \mathrm{~s}, 59{ }^{\circ} \mathrm{C}$ for $30 \mathrm{~s}$, then $72{ }^{\circ} \mathrm{C}$ for $4 \mathrm{~min}$, with a final elongation step of $72{ }^{\circ} \mathrm{C}$ for $10 \mathrm{~min}$. Following amplification, $20 \mu \mathrm{l}$ of product was digested with $R s a \mathrm{I}$ and the fragments separated on a $2 \%$ agarose gel. The restriction patterns identified either ST160 or SE1 and were confirmed by sequencing. 

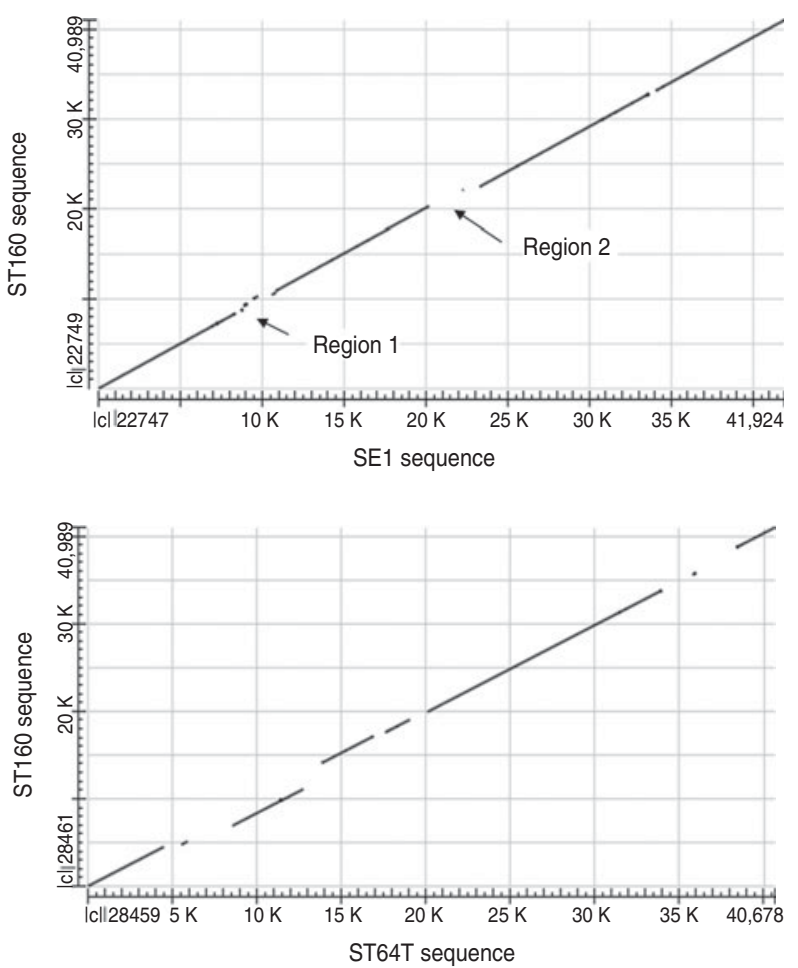

Fig. 1. Dot plot comparing genome sequence of ST160 with SE1 and ST64T generated using the NCBI BLAST search comparing two sequences and the dot plot generated as part of the output.

\section{Survey of $S$. Typhimurium and $S$. Enteritidis for susceptibility to ST160}

The serotypes of 640 suspected $S$. Typhimurium and $S$. Enteritidis isolates were identified according to the Kaufmann-White Scheme and then phage-typed $[16,17]$. A stock solution of $>10^{4}$ p.f.u. $/ \mathrm{ml}$ propagated phage ST160 was diluted and used alongside the reference phage panel during routine laboratory phagetyping of $S$. Typhimurium and $S$. Enteritidis isolates.

\section{RESULTS}

\section{Identifying differences between $S$. Typhimurium DT160 and LT2}

Within the 432 cloned fragments from the SSH library 41 contained sequences not present in LT2. The 41 clones contained 26 unique sequences and the majority of these $(14 / 26)$ were homologous $(\geqslant 99 \%)$ to sequences from the genome of P22 and the P22-like phages ST64T and ST104 [18]. These sequences and sequence from three other clones were subsequently found within the ST160 phage genome. The remaining sequences $(9 / 26)$ were closely related to the P27 group member, ST64B [18]. The results of the SSH

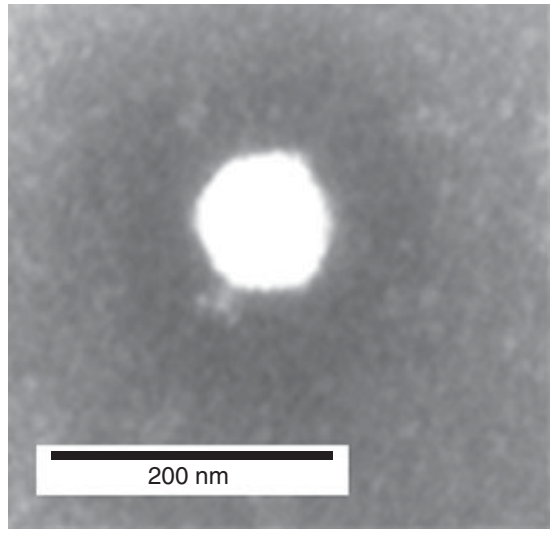

Fig. 2. Transmission electron micrograph of ST160 virions. Virions were prepared, negatively stained and examined as described in the Methods section.

experiment were confirmed by PCR using specific primers designed from the sequences of the clones (results not shown).

\section{Isolation of phage from $S$. Typhimurium DT160}

Propagation of the spent media from NZRM4347 on TT23564 gave three different plaque morphotypes that had a similar appearance but varied in size. Upon re-propagation, each morphotype gave the same mixture of different-sized plaques, and DNA from each morphotype gave the same restriction patterns when cut with EcoRI, BamHI, BglII, SalI and NcoI (data not shown). This novel phage isolate is hereafter referred to as ST160. Most S. Typhimurium DT160 isolates shed similar amounts of phages. Several notable exceptions included the Colindale $S$. Typhimurium DT160 type strain used as part of the $S$. Typhimurium phage-typing scheme, and two $S$. Typhimurium DT160 bird isolates from the USA and Denmark for which there were no observed plaques from the spent media of stationary phase cultures either with or without added mitomycin C. Further analysis of the Colindale $S$. Typhimurium DT160 type strain revealed sporadic release of detectable phage into log phase cultures, but no detectable phage from the same cultures when they reached stationary phase, suggesting a much lower level of spontaneous induction or perhaps less stable phage.

\section{Characterization of ST160 via TEM and generalized transduction assay}

TEM revealed that this phage has an icosahedralshaped head and very short tail (Fig. 2), making it a 
Table 2. Screening of isolates for the orf23 locus, ST160 or SE1 phage and shedding of ST160 phage

\begin{tabular}{|c|c|c|c|c|c|c|}
\hline $\begin{array}{l}\text { Serotype and strain or } \\
\text { phage type }\end{array}$ & $\begin{array}{l}\text { No. of isolates } \\
\text { characterized }\end{array}$ & Source & $\begin{array}{l}\text { orf } 23 \text { PCR } \\
\text { result* }\end{array}$ & $\begin{array}{l}\text { ST160 } \\
\text { or SE } \dagger\end{array}$ & $\begin{array}{l}\text { Southern blot } \\
\text { band size (kb) }\end{array}$ & $\begin{array}{l}\text { Shed } \\
\text { ST160: }\end{array}$ \\
\hline Typhimurium LT2 & 1 & ATCC & - & n.d. & No band & n.d. \\
\hline Typhimurium DT160 & 1 & Colindale, UK & + & SE1 & $7 \cdot 3$ & - \\
\hline Typhimurium DT74 & 1 & Colindale, UK & + & SE1 & n.d. & n.d. \\
\hline Typhimurium DT160 & 9 & $\mathrm{NZ}$ & + & ST160 & $12 \cdot 3$ & + \\
\hline Typhimurium DT160 & 2 & USA & + & ST160 & $12 \cdot 3$ & + \\
\hline Typhimurium DT160 & 1 & NZ & + & ST160 & $12 \cdot 3$ & - \\
\hline Typhimurium DT160 & 1 & USA & + & SE1 & $7 \cdot 3$ & - \\
\hline Typhimurium DT160 & 1 & Denmark & + & SE1 & $7 \cdot 3$ & - \\
\hline Typhimurium DT160 & 8 & USA & + & ST160 & n.d. & n.d. \\
\hline Typhimurium DT74 & 1 & NZ & + & ST160 & $12 \cdot 3$ & + \\
\hline Typhimurium RDNC-April06 & 1 & $\mathrm{NZ}$ & + & ST160 & n.d. & n.d. \\
\hline Typhimurium RDNC-May06 & 1 & $\mathrm{NZ}$ & - & n.d. & No band & n.d. \\
\hline Typhimurium DT101 & 1 & $\mathrm{NZ}$ & - & n.d. & No band & n.d. \\
\hline Typhimurium DT12a & 1 & $\mathrm{NZ}$ & - & n.d. & No band & n.d. \\
\hline Various serotypes§ & 19 & NZ & - & n.d. & No band & n.d. \\
\hline Bacteriophage P22 & 1 & TR6771 & - & n.d. & n.d. & n.d. \\
\hline Bacteriophage ST104 & 1 & NZRM3970 & - & n.d. & n.d. & n.d. \\
\hline Bacteriophage ST160 & 1 & NZRM4347 & + & n.d. & n.d. & n.d. \\
\hline
\end{tabular}

n.d., Not done.

* +, PCR product observed; -, no visible PCR product.

$\dagger$ The presence of ST160 or SE1 was determined by PCR of Region 1 and 2 and digestion of the products (see Material and Methods).

$\$+$, ST160 phage detected in spent media from an un-induced stationary phase culture;-, no ST160 phage detected in spent media from an un-induced stationary phase culture.

$\S$ Serotypes tested were Brandenburg, Saint Paul, Infantis, Mbandaka, Wangata, Javiana, Kiambu, Livingstone, Derby, Oranienburg, Rissen, Menston, Mississippi, Oslo, Virchow, Newport, Mana, Thompson, and Montevideo.

- NZRM, New Zealand Reference Culture Collection, ESR, Porirua, New Zealand.

member of the Podoviridae family [18]. A generalized transduction assay recovered between 200 and 500 chloramphenicol-resistant colonies from $10^{14}$ p.f.u., showing that ST160 was able to efficiently transfer a drug resistance marker between Salmonella strains.

\section{ST160 genome sequencing}

The 40986-bp genome of ST160 (Genbank accession number GU573886) had 64 identifiable ORFs (Supplementary Table 1, online). Genome analysis clearly shows that ST160 is most closely related to the P22like phages ( 834, ES18, P22, ST104, ST64T) including the recently deposited sequence of phage SE1 (accession number NC_011802). The overall GC content of phage ST160 was $47 \cdot 1 \%$ which is similar to the phages ST64T (47.5\%), SE1 (47.0\%), P22 (47.1\%) and ST104 $(47 \cdot 3 \%)$. ST160 is most closely related to ST64T and SE1, sharing 37 ORFs with SE1 and 36 ORFs with ST64T ( $\geqslant 99 \%$ identity at the amino-acid level). ST160 also shares nine ORFs with P22, and 20
ORFs with ST104 ( $\geqslant 99 \%$ identity at the amino-acid level).

The ST160 genome, like many other phages, has a mosaic structure. It contains eight ORFs which are identical to ORFs in the ST64T genome (orf66, kil, gp17, orf232, gp23, gp13, gp19, gp15) but have no homology to ORFs in the SE1 genome, and 12 ORFs that are identical to ORFs in SE1 (orf7, orf8, orf9, orf10, orf23, orf24, c2, cro, orf28, ninG, ninY, orf64) but little homology to ORFs in ST64T and some regions that are present in both of these phage genomes as well as in those of other P22-like phages. No unique ST160 ORFs were identified (Fig. 1).

\section{orf 23 assay}

An orf 23 PCR showed that all $S$. Typhimurium DT160 isolates were positive for orf 23 as were $S$. Typhimurium DT74 (seven isolates) and $S$. Typhimurium RDNC-April-06 (five isolates). All other isolates tested were negative (Table 2). Detection of the orf 23 target 


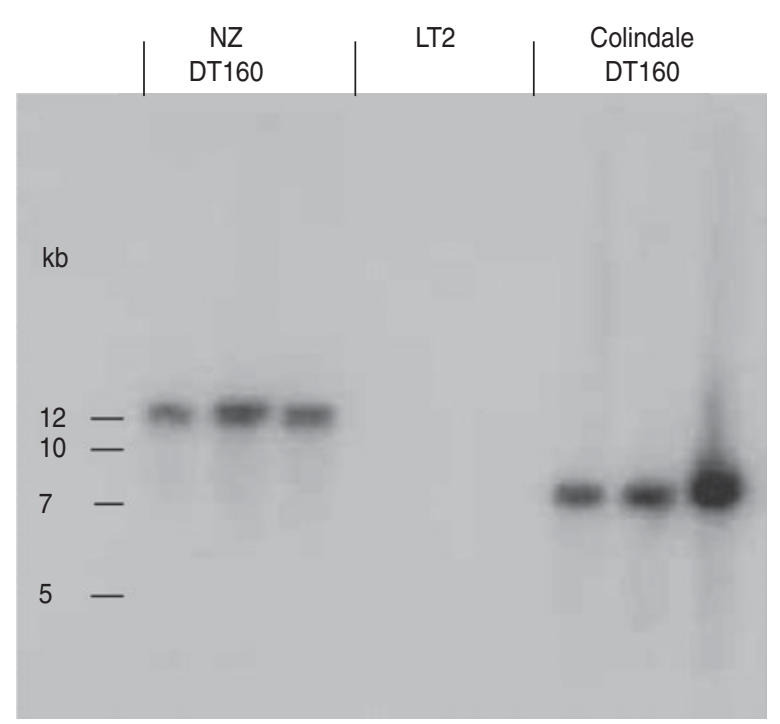

Fig. 3. Southern hybridization of the orf 23 region. A probe based on the $\operatorname{orf} 23$ gene from the ST160 genome sequence was used to screen Salmonella strains by Southern blot. The Southern blot of NcoI-digested DNA purified from cultures from three well isolated colonies of each indicated strain. $\mathrm{kb}$, Molecular size marker adjacent numbers indicate the fragment size in kilobases. All strains analysed had either no observable band (LT2 and most Salmonella serovars), the predicted $12 \cdot 3-\mathrm{kb}$ band (all New Zealand and some overseas $S$. Typhimurium DT160 isolates), or a $7 \cdot 3-\mathrm{kb}$ band (Colindale and some overseas isolates) (see Table 2).

in non-S. Typhimurium DT160 isolates indicates these strains may harbour ST160, SE1 or another closely related but as yet uncharacterized phage.

\section{Screen for the presence of orf 23 via Southern blot}

All $S$. Typhimurium DT160 isolates and a New Zealand $S$. Typhimurium DT74 isolate hybridized to an orf23-specific probe (Table 2). Two sizes of hybridizing fragment were observed, a $12 \cdot 3-\mathrm{kb}$ or a $7 \cdot 3-\mathrm{kb}$ fragment (Fig. 3). The New Zealand $S$. Typhimurium DT160 and DT74 isolates, and one US $S$. Typhimurium DT160 isolate gave the $12 \cdot 3-\mathrm{kb}$ hybridizing fragment in agreement with the ST160 genome sequence. The remaining overseas isolates tested, including a $S$. Typhimurium DT74 isolate from the UK, gave the 7-3-kb hybridizing fragment. All isolates with the $7 \cdot 3-\mathrm{kb}$ orf23-hybridizing fragment had SE1related sequences in the two regions of difference (Fig. 1) rather than ST160. These included the overseas isolates of $S$. Typhimurium DT160 from the USA and Denmark, the Colindale $S$. Typhimurium DT160 type strain and the Colindale $S$. Typhimurium DT74 type strain used in the $S$. Typhimurium phagetyping system. DNA purified from phage released by
Table 3. S. Typhimurium susceptibility to ST160

\begin{tabular}{|c|c|c|}
\hline $\begin{array}{l}\text { Phage } \\
\text { type* }\end{array}$ & $\begin{array}{l}\text { Number } \\
\text { sampled }\end{array}$ & Susceptibility \\
\hline 40 & 3 & +++ \\
\hline 64 & 1 & +++ \\
\hline 89 & 1 & +++ \\
\hline 135 & 21 & +++ \\
\hline 66 & 1 & ++ \\
\hline 153 & 1 & ++ \\
\hline 154 & 8 & ++ \\
\hline 42 & 91 & ++ \\
\hline 1 & 133 & + \\
\hline 9 & 31 & + \\
\hline 126 & 4 & + \\
\hline 155 & 7 & + \\
\hline PT1 & 6 & + \\
\hline 41 & 15 & + \\
\hline 156 & 79 & + \\
\hline 8 & 28 & + \\
\hline 78 & 1 & \pm \\
\hline 104 & 1 & - \\
\hline 29 & 2 & - \\
\hline 23 & 5 & - \\
\hline 22 & 1 & - \\
\hline $12 \mathrm{a}$ & 23 & - \\
\hline 6 & 2 & - \\
\hline 101 & 145 & - \\
\hline 74 & 29 & - \\
\hline $160 \dagger$ & 1 & - \\
\hline
\end{tabular}

,+++ Confluent lysis;,++ semi-confluent lysis; + , opaque lysis; - no lysis.

* All are $S$. Typhimurium except PT1 which is $S$. Enteritidis PT1.

$\dagger$ Colindale $S$. Typhimurium DT160 type strain.

the Colindale $S$. Typhimurium DT160 type strain had the $N c o$ I restriction pattern expected for SE1.

\section{Survey of $S$. Typhimurium and $S$. Enteritidis for susceptibility to ST160}

Susceptibility to ST160 was tested using 639 human and non-human isolates of $S$. Typhimurium and one $S$. Enteritidis (Table 3). Approximately 67\% (431/ 640) of strains tested were susceptible to ST160 including $S$. Typhimurium PT135 which at one time represented the most common phage type in New Zealand [19].

\section{DISCUSSION}

The first human case of $S$. Typhimurium DT160 in New Zealand was reported in 1998. Numbers of 
human cases rose steadily reaching a peak of 791 cases in 2001. The rapid increase in isolation rates of $S$. Typhimurium DT160 in the late 1990s and its continuing presence in both human and non-human isolates in New Zealand prompted our investigation into the potential factors facilitating the rapid spread of $S$. Typhimurium DT160. As a first step SSH was performed and this identified 26 DT160 specific fragments, all of which encoded genes that were homologous to genes from a variety of prophages. Thirteen of the SSH fragments identified were identical to those found by another group using LT2 and a New Zealand strain of DT160 following the same procedure [20]. To further characterize these differences, we isolated and sequenced ST160, a novel P22like phage, from $S$. Typhimurium DT160 cultures. Evaluation of the SSH data in light of the newly discovered ST160 genome sequence suggested that DT160 harboured two prophages that were not present in the genome of LT2, ST160 and ST64B.

Bacteriophage ST64B was initially isolated and characterized simultaneously with ST64T from $S$. Typhimurium DT64 [21]. ST64B and ST64T have a similar outward appearance and their genomes have a similar overall architecture, but individual gene sequences share no significant identity. In the nomenclature described by Kropinski and colleagues [18], ST64B is the single representative of the P27 group of Salmonella phages, since it most closely resembles the shigatoxin-carrying phage P27, as well as the serotype converting $S$. flexneri phage V with respect to its DNA packaging, capsid and tail genes. It is more closely related to phages $\mathrm{Mu}$ and Fels2 than it is to P22-like phages [8]. Despite numerous attempts on a variety of different Salmonella strains, ST64B has yet to be propagated. The tail and tail-sheath genes of ST64B are disrupted by fragments of genes from other organisms and TEM analysis showed that it fails to produce full-length tails [22]. The cryptic version of ST64B in $S$. Typhimurium ATCC14028s and SL1344 can be resuscitated to a viable form via a frame-shift mutation in the tail gene region [23]. Even though it is unable to lyse bacteria with a functional imm $C$ region, ST64B can influence the phage type of bacteria that harbour it [24]. Regions that are homologous to ST64B genome have been identified in numerous $S$. Typhimurium phage types [24] as well as in other Salmonella serotypes.

The ST160 phage genome, sequenced as part of this study, is a mosaic composed of genes that most closely resemble or are identical to genes in the
P22-like phage ST64T [25] or the SE1 phage. ST64T is a P22-like phage that was purified and characterized from a Salmonella strain commonly isolated in Australia, S. Typhimurium DT64 [21], but rarely found in New Zealand. ST64T is capable of infecting a variety of different Salmonella serovars. It can mediate phage-type conversion in lysogenized strains and can undergo generalized transduction, packaging and transfer of Salmonella DNA between host strains [21]. Bacteriophage SE1 was originally purified from an $S$. Enteritidis strain isolated from a hospitalized patient in Spain [26]. It can infect numerous Salmonella hosts influencing the properties of its bacterial host by facilitating lysogenic conversion, and also undergoes generalized transduction [26]. Like both ST64T and SE1 and other P22-like family members, ST160 was also found to be capable of efficient generalized transduction and is thus a potential vehicle for horizontal gene transfer. It can also infect a range of Salmonella hosts. ST160 shares $100 \%$ identity with $\mathrm{P} 22$ in the region encoding the P22 attP site, which includes the 46 identical base pairs of the att $B$ site within the thr $W$ tRNA gene [27-29] in Salmonella and other bacterial genomes. Thus ST160 integration is presumably via site-specific recombination within this thrW tRNA gene catalysed by bacterial integration host factor and phage-encoded integrase as demonstrated for P22 [28]. Approximately $36 \mathrm{~kb}$ of the $40-\mathrm{kb}$ ST160 genome are $98 \%$ identical to SE1 and the two regions in ST160 where SE1 and ST160 differ significantly are $100 \%$ identical to ST64T [apart from a difference in the number of 15-bp repeats in orf 232 in Region 1 and a 1-bp deletion in the 400-bp region between gp23 (antitermination protein) and gp13 (holin) of ST160 in Region 2] suggesting that the evolution of ST160 involved recombination between SE1 and ST64T.

Detection of ST160 in isolates was hampered by the lack of a ST160-specific target. The $\operatorname{orf} 23$ gene while originally thought to be specific for ST160 was also found in the recently released sequence of SE1. Using the gene as a marker for ST160, a survey of isolates showed that all $S$. Typhimurium DT160 isolates contained the gene. The gene was also present in other phage types, $S$. Typhimurium DT74 and $S$. Typhimurium RDNC-April06. This survey also revealed that the $S$. Typhimurium DT160 isolates were divided into those containing ST160 and those containing SE1. All New Zealand S. Typhimurium DT160, DT74 and RDNC-April06 isolates tested contained the ST160 phage. In addition, a number of recent 


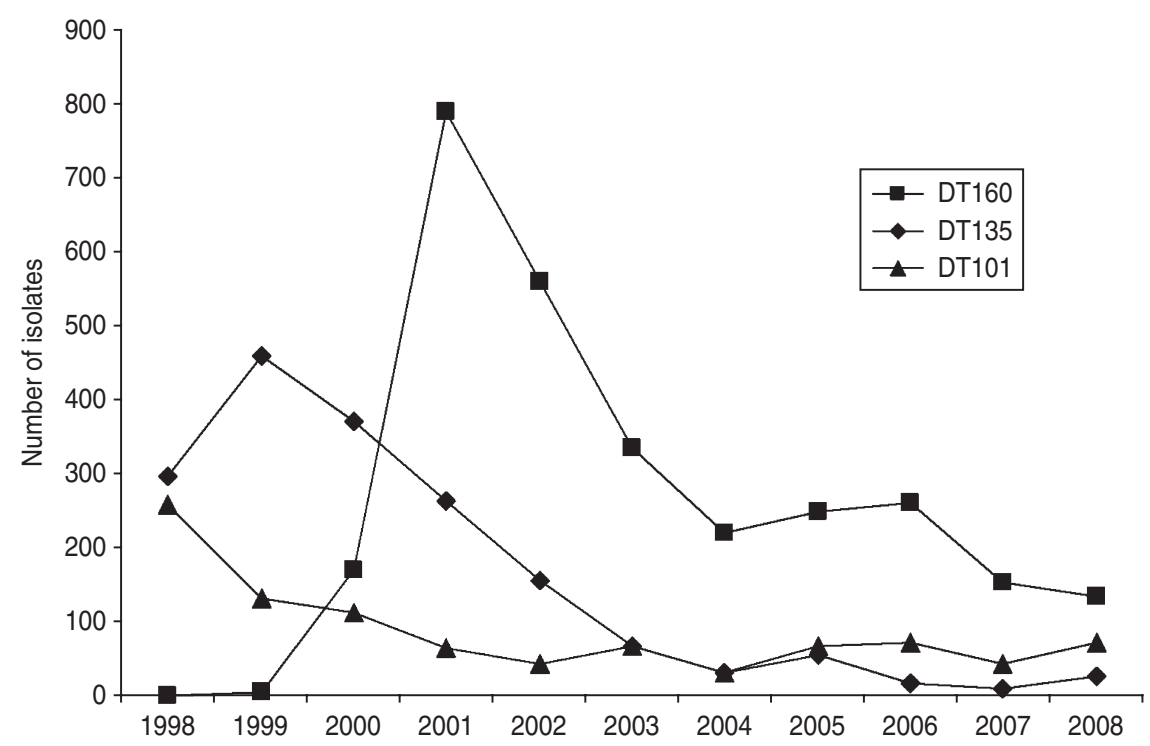

Fig. 4. Isolation of S. Typhimurium DT160, DT135 and DT101 from patients in New Zealand from 1998 to 2008.

isolates from the USA (Table 2) also contained ST160 as judged by the orf 23 PCR and Regions 1 and 2 differentiating PCR. All SE1-containing isolates originated from outside New Zealand and included the $S$. Typhimurium DT160 and DT74 type strains from Colindale used as part of the $S$. Typhimurium phagetyping scheme and two $S$. Typhimurium DT160 isolates from birds, one from the USA and one from Denmark. Stationary phase cultures of all but one New Zealand DT160 isolates contained detectable ST160 phages. One $S$. Typhimurium DT160 isolate from New Zealand harboured ST160 as judged by Southern blot analysis but failed to shed detectable phage into stationary phase culture medium (Table 2). It was not possible to detect viable phage in stationary phase cultures of $S$. Typhimurium DT160 isolates harbouring SE1.

All New Zealand strains of $S$. Typhimurium DT160 are indistinguishable by PFGE suggesting clonal spread of the organism in animal and human populations [2]. Differences were identified in the macrorestriction profiles of New Zealand $S$. Typhimurium DT160 and those from abroad but they were deemed to be related. It is not apparent why $S$. Typhimurium DT160 should be so prolific in New Zealand yet remain relatively innocuous elsewhere. Many $S$. Typhimurium phage types and at least one $S$. Enteritidis phage type were lysed by ST160 but a number of $S$. Typhimurium strains were resistant, suggesting these strains may harbour prophage(s) which conveys resistance to ST160 (Table 3). The immC region of ST160 is identical to that of ST104 and ST64T which explains the resistance of $S$. Typhimurium DT104 to ST160.

Bacteriophage ST160 was shown to be constitutively shed in culture and this shedding may provide $S$. Typhimurium DT160 with a competitive advantage over susceptible $S$. Typhimurium phage types. One possibility is that some of the strains of Salmonella circulating in New Zealand at the time the ST160containing isolate was introduced were sensitive to the phage and this enabled $S$. Typhimurium DT160 to expand rapidly. The role of phage in promoting resistant strains under competitive colonization conditions has been demonstrated in Salmonella [30] and Campylobacter [31]. A survey of strains that are sensitive and resistant to ST160 (Table 3) shows that around the time $S$. Typhimurium DT160 was introduced the major types circulating in New Zealand among humans and animals were $S$. Typhimurium DT135, DT101 and DT1. $S$. Typhimurium DT101 is resistant to the ST160 phage, but $S$. Typhimurium DT1 and DT135 are sensitive. The number of human infections caused by $S$. Typhimurium DT135 and DT1 fell after 2000 whereas the number of $S$. Typhimurium DT101 infections remained constant (Fig. 4). While this is anecdotal evidence it is interesting to note that the major causes of salmonellosis elsewhere in the world are resistant to ST160.

Both S. Typhimurium DT74 and RDNC-April2006 are rare phage types with very few reports of infections or outbreaks; no cases of $S$. Typhimurium DT74 have yet been identified in Australia (G. Hogg, personal communication). The observation that the 
New Zealand isolates of $S$. Typhimurium DT160 and DT74 contained ST160 whereas the Colindale $S$. Typhimurium DT160 and DT74 type strains contained SE1-like sequences suggests that the two phage types are closely related. Given that, in New Zealand, $S$. Typhimurium DT74 emerged after $S$. Typhimurium DT160 it is possible that $S$. Typhimurium DT74 may evolve from $S$. Typhimurium DT160 via a loss or gain of a phage(s) giving rise to the small difference in the phage-typing pattern. A change in definitive phage type due to acquisition of particular phages has been described previously [21]. The emergence of other phage types such as RDNC-April06 containing ST160 reflects the spread and uptake of the phage within the New Zealand $S$. Typhimurium population. The emergence and decline of epidemic strains of Salmonella has been described [32] and is due to a number of factors including acquisition of virulence factors [33] but susceptibility to new phages may well be critical to changes in $S$. Typhimurium populations.

The evidence presented in this study shows that there is more than one distinguishable type of $S$. Typhimurium DT160. The evolution of this definitive type has had a significant impact on both human and animal health in New Zealand. To understand the risks posed by newly emerging strains of Salmonella requires not only knowledge of their genetic make-up but also knowledge of the Salmonella population into which the new strain emerges.

\section{NOTE}

Supplementary material accompanies this paper on the Journal's website (http://journals.cambridge.org/ hyg).

\section{ACKNOWLEDGEMENTS}

This work was part funded from the ESR and AgResearch Capability Fund provided by the Foundation for Research Science and Technology. We thank Marilyn Grubner at ESR for helping with sequencing of the SSH library, Doug Harcroft for TEM and John Roth for the phage-deficient chloramphenicol-resistant LT2 strain.

\section{DECLARATION OF INTEREST}

None.

\section{REFERENCES}

1. Girard MP, et al. A review of vaccine research and development: human enteric infections. Vaccine 2006; 24: 2732-2750.

2. Alley MR, et al. An epidemic of salmonellosis caused by Salmonella Typhimurium DT160 in wild birds and humans in New Zealand. New Zealand Veterinary Journal 2002; 50: 170-176.

3. Callaghan MS, Simmons G. Outbreak of Salmonella Typhimurium Phage type 160 in Auckland linked to an umu function. New Zealand Public Health Report 2001; 8: 44-45.

4. Li H, McFarlane RG, Wagner J. Vaccination of pregnant ewes against infection with Salmonella Brandenburg. New Zealand Veterinary Journal 2005; 53: $416-422$.

5. Hermans AP, et al. Identification of novel Salmonella enterica serovar Typhimurium DT104-specific prophage and nonprophage chromosomal sequences among serovar Typhimurium isolates by genomic subtractive hybridization. Applied and Environmental Microbiology 2005; 71 : 4979-4985.

6. Yokoyama E, et al. Prevalence and genetic properties of Salmonella enterica serovar typhimurium definitive phage type 104 isolated from Rattus norvegicus and Rattus rattus house rats in Yokohama City, Japan. Applied and Environmental Microbiology 2007; 73: 2624-2630.

7. Anon. Notifiable and other diseases in New Zealand. ESR Annual Report 2001 (http://www.surv.esr.cri.nz/PDF surveillance/AnnualRpt/AnnualSurv/2001AnnualSurvRpt. pdf.2002). Accessed 17 March 2010.

8. Anon. Notifiable and other diseases in New Zealand. ESR Annual Report 2006 (http://www.surv.esr.cri.nz/PDF surveillance/AnnSurvRpt/2006AnnualSurvRpt.pdf.2007). Accessed 17 March 2010.

9. Thornley CN, et al. First incursion of Salmonella enterica serotype typhimurium DT160 into New Zealand. Emerging Infectious Disease 2003 ; 9: 493-495.

10. Connolly JH, et al. Infectivity and persistence of an outbreak strain of Salmonella enterica serotype Typhimurium DT160 for house sparrows (Passer domesticus) in New Zealand. New Zealand Veterinary Journal 2006; 54: 329-332.

11. Frye JG, et al. Host gene expression changes and DNA amplification during temperate phage induction. Journal of Bacteriology 2005; 187: 1485-1492.

12. Davis RW, Botstein D, Roth JR. Advanced Bacterial Genetics. Cold Spring Harbor, NY: Cold Spring Harbor Laboratory, 1980.

13. Ausubel FM, et al. Current Protocols in Molecular Biology. New York: John Wiley \& Sons Inc., 1994.

14. Altschul SF, et al. Gapped BLAST and PSI-BLAST: a new generation of protein database search programs. Nucleic Acids Research 1997; 25: 3389 3402 .

15. Lukashin AV, Borodovsky M. GeneMark.hmm: new solutions for gene finding. Nucleic Acids Research 1998; 26: $1107-1115$. 
16. Callow BR. A new phage-typing scheme for Salmonella typhimurium. Journal of Hygiene 1959; 57: 346-359.

17. Anderson ES, et al. Bacteriophage-typing designations of Salmonella typhimurium. Journal of Hygiene 1977; 78: 297-300.

18. Kropinski AM, et al. Salmonella phages and prophagesgenomics and practical aspects. In: Schatten $\mathrm{H}$, Eisenstark A, eds. Salmonella. Clifton, NJ: Springer, 2007, pp. 133-175 (Methods in Molecular Biology, vol. 394).

19. Thornley C, Baker M, Nicol C. The rising incidence of salmonella infection in New Zealand, 1995-2001. New Zealand Public Health Report 2003; 9: 25-28.

20. Kang MS, et al. Identification of specific gene sequences conserved in contemporary epidemic strains of Salmonella enterica. Applied and Environmental Microbiology 2006; 72: 6938-6947.

21. Mmolawa PT, et al. Temperate phages in Salmonella enterica serovar Typhimurium: implications for epidemiology. International Journal of Medical Microbio$\log y$ 2002; 291 : 633-644.

22. Mmolawa PT, Schmieger H, Heuzenroeder MW. Bacteriophage ST64B, a genetic mosaic of genes from diverse sources isolated from Salmonella enterica serovar typhimurium DT 64. Journal of Bacteriology 2003; 185: 6481-6485.

23. Figueroa-Bossi N, Bossi L. Resuscitation of a defective prophage in Salmonella cocultures. Journal of Bacteriology 2004; 186: 4038-4041.

24. Tucker CP, Heuzenroeder MW. ST64B is a defective bacteriophage in Salmonella enterica serovar Typhimurium DT64 that encodes a functional immunity region capable of mediating phage-type conversion. International Journal of Medical Microbiology 2004; 294: 59-63.
25. Mmolawa PT, et al. Genomic structure of the Salmonella enterica serovar Typhimurium DT 64 bacteriophage ST64T: evidence for modular genetic architecture. Journal of Bacteriology 2003; 185: 3473 3475 .

26. Llagostera M, Barbe J, Guerrero R. Characterization of SE1, a new general transducing phage of Salmonella typhimurium. Journal of General Microbiology 1986; 132: 1035-1041.

27. Leong JM, et al. The phi 80 and P22 attachment sites. Primary structure and interaction with Escherichia coli integration host factor. Journal of Biological Chemistry 1985; 260: 4468-4477.

28. Smith-Mungo L, Chan IT, Landy A. Structure of the P22 att site. Conservation and divergence in the lambda motif of recombinogenic complexes. Journal of Biological Chemistry 1994; 269: 20798-20805.

29. Vander Byl C, Kropinski AM. Sequence of the genome of salmonella bacteriophage P22. Journal of Bacteriology 2000; 182: 6472-6481.

30. Bossi L, et al. Prophage contribution to bacterial population dynamics. Journal of Bacteriology 2003; 185: 6467-6471.

31. Scott AE, et al. Bacteriophage influence Campylobacter jejuni types populating broiler chickens. Environmental Microbiology 2007; 9: 2341-2353.

32. Brussow H, Canchaya C, Hardt WD. Phages and the evolution of bacterial pathogens: from genomic rearrangements to lysogenic conversion. Microbiology and Molecular Biology Reviews 2004; 68: 560602.

33. Figueroa-Bossi N, et al. Variable assortment of prophages provides a transferable repertoire of pathogenic determinants in Salmonella. Molecular Microbiology $2001 ; 39$ : 260-271. 